\title{
Shifting The Paradigm: Nepal as a Potential Leader in The Field of Medical Education
}

\author{
Dr Biraj Man Karmacharya \\ Department of Community Medicine \\ Kathmandu University School of Medical Sciences, Dhulikhel Hospital
}

The last two decades have seen a tremendous boom of medical colleges in Nepal. Before 1993, Institute of Medicine, Maharajgunj was the sole national institution for medical education for almost 15 years. In the year 1993, BP Koirala Institute of Health Sciences, Dharan was established and this was soon followed by a rapid increase in the number of affiliated medical colleges of Kathmandu University and also Tribhuwan University later. Meanwhile, Kathmandu University also started its own medical college, Kathmandu University Medical School (KUMS) in 2001 and Patan Academy of Health Sciences was established in 2008. ${ }^{1}$

This development of medical colleges in recent times is no doubt a feat for a small developing country like ours where resource limitation together with dearth of human resources posed seemingly unsurmountable challenge. Nobody would have imagined few decades back that Nepal can be a destination of medical education, one of the most difficult and complex fields in educational sectors, for students from other countries as well. The way non-governmental sectors harnessed the potentials of partnerships with neighbouring countries (particularly India) for human resources and the way government facilitated these endeavors should be a model for other countries too. Moreover, the diversity of teaching methodologies that these institutions have been following or have decided to follow, makes Nepal a unique ground for exploring the strengths, limitations and innovations related to these systems. Of particular relevance in this context are problem based learning and community based learning.

Problem-Based Learning (PBL) is a method of learning in which students first encounter a problem, followed by a student-centered inquiry process. Both content and the process of learning are emphasized in PBL. Although many variants of PBL have developed during the past decades, its essential elements have remained relatively constant. Typically, five to eight students work collaboratively in a group (tutorial), together with one or more faculty facilitators (tutors), to identify and define problems, develop hypotheses to explain the problem (s), and explore preexisting knowledge relevant to the issues. 2,3

Generally a problem is a description of a set of phenomena or events that can be perceived in reality. The phenomena that are described have to be analyzed in terms of underlying principles, mechanisms or processes. This is accomplished in the tutorial group by discussion of the problem, the activation of prior knowledge and the formulation of learning objectives. The group process is followed by individual study of the relevant information resources. Finally, the results of the self-directed learning are reported in the tutorial group, the knowledge is integrated, and it is checked to ensure the objectives of the problems have been met. ${ }^{4}$

Variants of problem based learning approach have been adopted by the medical colleges in Nepal and this is being expanded in recent years as well. Planned expansion of PBL in the affiliated colleges of Kathmandu University will again be a big leap in this context. It is noteworthy that, although a huge majority of current academic circle were trained in non-PBL teaching system, the commitment for learning and trying out this in the current system of medical education is laudable. In fact, in this matter, Nepal is ahead of the neighbouring countries and in future, there are ample opportunities to use our diverse experience for the training programmes related to Health Professions Education for the neighbouring countries and also other countries in the world that are keen to explore the possibilities of implementing such approaches.

Community based medical education is 'focused on population groups and individual persons taking into account the health needs of the community concerned'. ${ }^{5}$ It stresses the wider determinants of health, which are often rooted in the community, and embraces the holistic biopsychosocial model of health. Closely related to this philosophy is the patient-centred care movement pioneered by Levenstein and Stewart. ${ }^{6}$ During their academic years, the students are supposed to spend some time in the community and also in the rural level health centers. During their postings in such places, they explore and address the health needs and problems of the community more through prevention strategies and primary care level; thus, in a more holistic way. Exposure to the communities in rural setup during undergraduate teaching of medical students may help them in appreciating the primary health-care needs of the community. ${ }^{7}$ During these activities, the students 
also participate and contribute by different ways to the primary health care activities in the community. One of the examples is to take the responsibility of few primary health centres, sub-health posts and health posts in the vicinity and send the staffs and the students of the medical colleges there. This team from the medical colleges can enhance the service part of the centres and can also conduct complementing activities from the ground level in the community

Right from the initiation of the first medical college of Nepal (i.e., IOM in 1978), medical education programs were supposed to be very much community based, although there was initial opposition to the program that this being 'WHO inspired and community oriented' would lead to the production of sub-standard medical manpower. ${ }^{1}$ Despite this, the commitment to the community based approaches has remained undeterred and the institutions in Nepal have tried to implement such strategies in a range of different ways. ${ }^{8}$ However, very surprisingly there is still lack of clear guidelines and assessment tools on the community based programs of education in the medical colleges. When compared to the criteria on clinical set-up, basic sciences laboratory set-up and the faculty, very few objective criteria and guidelines are present/functional in the assessment of the community based programs of the medical colleges. One of the reasons for this is the complexity and the multi-factorial nature of the community based approaches unlike the possibilities of clear objective parameters for the clinical and laboratory set-ups. This has definitely created serious lack of quality control measures of the CBL programs. Given the possibilities of the contribution of the community based learning programs in the primary health care level of the country, it can be well appreciated that the immense potential of these institutions in the development of the primary health care sector in national level has been hugely untapped.

If arrangements can be made to make the secondary and tertiary level hospitals take the responsibility (of various degrees) of at least two to three peripheral level centres (which is of course not a big burden in terms of management and also finances), the primary level health sector in Nepal will have significant changes. For the teaching institutions (e.g., the medical colleges), this will also be a win-win situation because the primary level centres can also be integrated in various training activities for the students. The major area of possibility in this context is the usage of community based learning technique in the medical colleges. This sort of community based approach will be the main bridge between the spheres of two health systems: the moreor-less autonomous medical colleges and the governmental health system.

The model of linkage between primary and higher level health sector, if proved to be successful can also be replicated in other developing countries all around the world. This also ensures that the unstoppable fast growth of larger hospitals and the medical colleges even in the developing countries can be tapped for the benefit of primary health care. This will prove to be a very cost-effective and manageable solution to address at least some of the major problems of primary health care in Nepal and around the world in developing countries.

Hence, let us understand that there is immense potential within us to lead and be models for the world, particularly for the developing countries that are still following the steps that we have already taken. To do so, there needs to be a paradigm shift in the way the policy makers and the professionals working in medical field view the whole sphere of medical education. Rather than being rivals, let all these stakeholders work in team to understand the strengths and limitations of each other and lead the field that even few years back seemed to be a distant dream for us.

\section{REFERENCES}

1. Dixit H. Nepal's Quest for Health. Educational Publications, 2005.

2. Neufeld VR, Barrows HS. "The McMaster philosophy": An approach to medical education. Journal of Medical Education 1974; 49(11):1040-50.

3. Schmidt HG. Foundations of problem-based learning: some explanatory notes. Medical Education 1993; 27: 422-32.

4. de Goeij AFPM. Problem-based learning: what is it? what is it not? what about the basic sciences? Biochemical Society Transaction 1997;25: 288-93.

5. Hamad B. Community-oriented medical education: what is it? Med Educ 1991;25:16-22.

6. Stewart M, Brown JB, et al. Patient Centred Medicine: Transforming the Clinical Method. Thousand Oaks, California:Sage Publications; 1995.

7. Fraser RC. Undergraduate medical education: Present state and future needs. BMJ 1991;303:41-3.

8. Marahatta SB, Sinha NP, Dixit H, Shrestha IB, Pokharel PK. Comparative study of community medicine practice in MBBS curriculum of health institutions of Nepal. Kathmandu Univ Med J 2009;28, 461-69. 